\title{
Cerebrovascular disease: Collaboration between neurologists and vascular surgeons in Mexico
}

\section{Enfermedad cerebrovascular: colaboración entre neurólogos y angiólogos en México}

\author{
Amado Jiménez-Ruiz ${ }^{*}$, Miguel García-Grimshaw², and José L. Ruiz-Sandoval ${ }^{3}$ \\ ${ }^{1}$ Stroke, Dementia and Heart Disease Laboratory, Western University, London, Ontario, Canada; ${ }^{2}$ Department of Neurology and Psychiatry, Instituto \\ Nacional de Ciencias Médicas y Nutrición “Salvador Zubirán”, Mexico City, Mexico; ${ }^{3}$ Department of Neurology, Hospital Civil Fray Antonio Alcalde, \\ Guadalajara, Jalisco, Mexico
}

"Coming together is a beginning, staying together is progress, and working together is success."

-Henry Ford (1863-1947)

Today's medical field is highly subspecialized, and what is gained in depth is often lost in extension. Multidisciplinary teamwork provides the most crucial framework for holistic medical care models that meet patients' demands who suffer from vascular disease, especially in resource-limited settings.

Cerebrovascular disease (CVD) is the leading cause of death and disability worldwide, posing a substantial economic burden on health systems ${ }^{1}$. In Mexico, CVD remains understudied and available data show great variability in diagnostic and therapeutic strategies. The cumulative incidence of CVD in Mexico is 232/100,000 inhabitants, while the prevalence among people $\geq 60$ years is $18 / 1000$ inhabitants ${ }^{2,3}$.

The important role of vascular surgeons in the diagnosis and management of CVD is recognized among neurologists, especially in conditions such as aortic arch and supra-aortic trunk disease (including carotid artery disease). Atherosclerotic carotid disease is a common cause of transient ischemic attack and stroke whose management includes medical and surgical treatment, depending on the degree of stenosis and presence or absence of symptoms. Carotid endarterectomy with patch angioplasty and carotid stenting has emerged as essential revascularization techniques in primary and secondary stroke prevention.

Aortic arch disease may result in several neurological manifestations associated with primary vessel disorders (embolism, dissection, aneurysms, and vasculitis) and complications of its surgical management where participation between vascular neurologists and vascular surgeons is critical.

Vascular risk factors affect the entire economy of the body, and vascular disease is often multifocal, affecting carotid arteries, intracranial brain arteries, coronary arteries, aorta, and peripheral arteries. It is not uncommon for a patient with a stroke to suffer from ischemic heart disease and peripheral artery disease. Morbidity and mortality are much higher in patients with multifocal artery disease than unifocal ${ }^{4,5}$.

Undoubtedly, the management of vascular disease requires a multidisciplinary team to treat the risk factors present in each patient (diabetes mellitus, high blood pressure, dyslipidemia, smoking, atrial fibrillation, obesity, etc.). Primary care physicians should be alert to the possibility of silent multifocal disease in patients with an apparent monovascular disorder. This model requires integrating various specialists responsible for the 
Rev Mex Angiol. 2021;49(2)

diagnosis and treatment of different forms of vascular disease; including vascular surgery, cardiology, and neurology.

\section{Solidarity is our strength.}

\section{References}

1. Johnson CO, Nguyen M, Roth GA, Nichols E, Alam T, Abate D, et al. Global, regional, and national burden of stroke, 1990-2016: a systematic analysis for the Global Burden of Disease Study 2016. Lancet Neurol. 2019;18:439-58

2. Marquez-Romero JM, Arauz A, Góngora-Rivera F, Barinagarrementeria F, Cantú C. The burden of stroke in México. Int J Stroke. 2015;10:251-2.

3. Cantu-Brito C, Majersik JJ, Sánchez BN, Ruano A, Becerra-Mendoza D, Wing JJ, et al. Door-to-door capture of incident and prevalent stroke cases in Durango, Mexico: the Brain Attack Surveillance in Durango Study. Stroke. 2011:42:601-6.

4. Paraskevas KI, Geroulakos G, Veith FJ, Mikhailidis DP. Multifocal arterial disease: clinical implications and management. Curr Opin Cardiol. 2020;35:412-6.

5. Paraskevas KI, Nordon IM, Baxter SJ, Shearman CP, Phillips MJ. Abdominal aortic aneurysms, peripheral arterial disease, and carotid artery stenosis: different sides of the same coin? Angiology. 2016;67:307-8. 